\title{
REVESTIMENTO COMESTÍVEL À BASE DE GOMA XANTANA, COMPOSTOS LIPOFÍLICOS E/OU CLORETO DE CÁLCIO NA CONSERVAÇÃO DE MORANGOS ${ }^{1}$
}

\author{
BIANCA SÁVIA FERREIRA LEITE2 ${ }^{2}$, CAROLINE DELLINGHAUSEN BORGES ${ }^{3}$, \\ PATRÍCIA GONÇALVES BAPTISTA CARVALHO ${ }^{4}$, NEIDE BOTREL $^{5}$
}

RESUMO - Objetivou-se com este estudo avaliar revestimentos comestíveis à base de goma xantana e glicerol, combinada a cloreto de cálcio, ácido oleico e/ou óleo essencial de hortelã-pimenta na conservação de morangos cv. Festival. Os morangos foram selecionados, lavados, sanitizados e, a seguir, submetidos a diferentes tratamentos de revestimentos à base de goma xantana acrescidos de glicerol, cloreto de cálcio, ácido oleico e/ou óleo essencial de hortelã-pimenta. Os frutos foram secos sob ventilação forçada a $4{ }^{\circ} \mathrm{C}$, por $15 \mathrm{~h}$, e, posteriormente, embalados em bandejas com tampa de Polietileno Tereftalato (PET) e armazenados a $4{ }^{\circ} \mathrm{C}$, durante 12 dias. Foram realizadas análises de perda de massa, firmeza, luminosidade, tonalidade, $\mathrm{pH}$, acidez, sólidos solúveis totais, antocianinas e a incidência de deterioração fúngica. Os diferentes revestimentos utilizados foram eficientes na conservação dos morangos. O tratamento com goma xantana e glicerol apresentou os melhores resultados, pois a influência do ácido oleico ou do óleo essencial de hortelãpimenta, assim como do cloreto de cálcio, não foi significativa. O revestimento de goma xantana proporcionou redução da perda de massa, manutenção da firmeza, cor, pH, acidez, sólidos solúveis totais, antocianinas e não estimulou o crescimento fúngico. Desta forma, esta goma apresenta potencial para aplicação como revestimento em morangos, visando a maximizar a vida útil deste produto.

Termos de indexação: Fragaria x ananassa Duch., Mentha piperita L., ácido oleico, perda de massa, deterioração fúngica.

\section{EDIBLE COATING BASED ON XANTHAN GUM, LIPOPHILIC COMPOUNDS AND/OR CALCIUM CHLORIDE IN THE STRAWBERRIES PRESERVATION}

\begin{abstract}
It was aimed with this study to evaluate the edible coating based on xanthan gum and glycerol, combined the calcium chloride, oleic acid and/or peppermint essential oil, in the preservation of strawberries cv. Festival. Strawberries were selected, washed, sanitized, and after the fruits were subjected to different xanthan based coating treatments containing glycerol, calcium chloride, oleic acid and/or peppermint essential oil. Fruits were dried under forced ventilation at $4{ }^{\circ} \mathrm{C}$ for $15 \mathrm{~h}$ and, after, packed in polyethylene terephthalate trays and stored at $4{ }^{\circ} \mathrm{C}$ for 12 days. Analyses of weight loss, firmness, color, $\mathrm{pH}$, titratable acidity, total soluble solids, anthocyanin concentration and incidence of decay were realized. All coatings tested were efficient in maintaining fruit quality. The best treatment was xanthan gum and glycerol, since the addition of oleic acid, peppermint essential oil and calcium chloride was not significant. Xanthan gum coating provided reduction of weight loss, maintained firmness, color, pH, titratable acidity, total soluble solids and anthocyanin concentration and did not stimulate fungal growth. Thus, this gum has potential for application as a coating in strawberries cv. Festival to maximize the useful life of this product.
\end{abstract}

Index terms: Fragaria $x$ ananassa Duch, Mentha piperita L., oleic acid, weight loss, fungal decay

${ }^{1}$ (Trabalho 228-14). Recebido em: 02-09-2014. Aceito para publicação em: 16-03-2015.

${ }^{2}$ Química, Discente do Curso de Especialização em Ciência dos Alimentos, Universidade Federal de Pelotas. E-mail:biancasavia@ gmail.com

${ }^{3}$ Química de Alimentos; Doutorado em Biotecnologia Agrícola; Docente da Universidade Federal de Pelotas. E-mail: caroldellin@ bol.com.br

${ }^{4}$ Bióloga, Doutorado em Biologia Molecular, Pesquisadora da Embrapa Hortaliças. E-mail: patricia.carvalho@embrapa.br

${ }^{5}$ Engenheira Agrônoma, Doutorado em Ciência dos Alimentos, Pesquisadora da Embrapa Hortaliças. E-mail: neide.botrel@embrapa.br 


\section{INTRODUÇÃO}

O morango é um fruto de clima temperado, com gosto e aroma agradáveis e textura suculenta, sendo por isso muito apreciado e valorizado (BERBARI et al.,1998). Entretanto, apresenta alta perecibilidade, sensibilidade ao dano mecânico, desenvolvimento fúngico, desidratação e perda de firmeza. Essas alterações causam redução na qualidade do fruto, diminuindo sua aceitação e limitando seu período de estocagem (BERBARI et al.,1998; COSTA, 2009). Assim, esse fruto deve ser armazenado sob refrigeração de 4 a $5^{\circ} \mathrm{C}$, o que pode estender a qualidade por apenas 6 a 7 dias (TANADA-PALMU; GROSSO, 2005).

Uma alternativa para auxiliar no controle das alterações pós-colheita do morango é o emprego de revestimentos, os quais têm sido estudados com objetivo de ampliar a vida útil de diversas frutas e hortaliças, promovendo a manutenção de sua qualidade por um período mais longo. No entanto, compostos de cálcio têm sido acrescentados com a finalidade de aumentar a firmeza e o controle do desenvolvimento fúngico (TANADA-PALMU; GROSSO, 2005; COSTA, 2009).

Revestimentos comestíveis são definidos como uma fina camada de material comestível, aplicados e formados diretamente na superfície do produto. São utilizados, entre outras funções, para inibir a migração da umidade, oxigênio, dióxido de carbono, aromas e lipídeos (KROCHTA; MULDER-JOHNSTON, 1997). Além disto, podem ser utilizados como carreadores de aditivos, como antioxidantes, antimicrobianos, entre outros.

Em morangos, a quitosana tem sido o principal polissacarídeo utilizado como revestimento (HAN et al., 2004; HERNÁNDEZ-MUÑOZ et al., 2006; VARGAS et al., 2006; CAMPANIELLO et al., 2008; HERNÁNDEZ-MUÑOZ et al., 2008; VU et al., 2011). Além desta, fécula de mandioca (HENRIQUE; CEREDA, 1999); mucilagem de cáctus (DEL-VALLE et al., 2005); glúten (TANADA-PALMU; GROSSO, 2005); soro de leite (OLIVEIRA et al., 2008); alginato (FAN et al., 2009); amido e carragena (RIBEIRO et al., 2007) já foram avaliados.

A goma xantana é um polissacarídeo produzido por espécies de bactérias do gênero Xanthomonas, normalmente, Xanthomonas campestris pv campestris. É solúvel em água fria ou quente e apresenta estabilidade em relação à variação de temperatura, $\mathrm{pH}$ e força iônica. Essa goma tem sido utilizada em diversos produtos como um agente espessante e estabilizante (GARCÍA-OCHOA et al., 2000). A goma xantana já foi utilizada como revestimento comestível em mamão (CORTEZVEJA et al., 2013), maçã (FREITAS et al., 2013), pêssego (PIZATO et al., 2013) e morangos (BORGES et al., 2013) minimamente processados; entretanto, os resultados são dependentes da fruta, assim como dos aditivos utilizados.

De acordo com Vu et al. (2011), normalmente, os revestimentos são à base de polissacarídeos ou proteínas, e estes atuam, principalmente, mantendo a umidade e estendendo a vida de prateleira. Entretanto, a natureza hidrofílica destes componentes limita sua capacidade de formar um revestimento com características desejáveis. A adição de materiais lipídicos ao revestimento hidrofílico pode, algumas vezes, melhorar as propriedades de barreira à umidade (AMARANTE; BANKS, 2001). Além disto, o ácido oleico (DAVIDSON et al., 1999; VARGAS et al., 2006) e o óleo essencial de hortelãpimenta (PEREIRA et al., 2006; YADEGARINIA et al., 2006; SINGH et al., 2011) apresentam atividade antimicrobiana. Desta forma, objetivou-se com este estudo avaliar revestimentos comestíveis à base de goma xantana e glicerol combinada a cloreto de cálcio, ácido oleico e/ou óleo essencial de hortelãpimenta na conservação de morangos cv. Festival.

\section{MATERIAL E MÉTODOS}

Foram utilizados morangos (Fragaria $x$ ananassa Duch.), cultivar Festival, adquiridos diretamente de um produtor de Brazlândia-DF. Os frutos foram transportados para o Laboratório de Ciências e Tecnologia de Alimentos - Embrapa Hortaliças (Gama-DF), onde foi realizado o processamento. Os morangos foram selecionados quanto à ausência de defeitos fisiológicos, tamanho e cor $(>75 \%$ da superfície de coloração vermelha). A sépala e o pedicelo foram cortados, para seguir a lavagem e sanitização em solução de dicloroisocianurato de sódio $200 \mathrm{mg} \mathrm{L}^{-1}$, por 15 minutos.

A goma xantana (Ziboxan RD) foi preparada por dissolução lenta em água destilada, à temperatura ambiente, sob agitação constante por $2 \mathrm{~h}$; posteriormente, a solução foi submetida ao aquecimento por 20 minutos, a $60^{\circ} \mathrm{C}$. A solução foi armazenada sob refrigeração a $4{ }^{\circ} \mathrm{C}$, por $24 \mathrm{~h}$. No momento da utilização, foram adicionados o glicerol (Vetec), utilizado como plastificante, o ácido oleico (Synth) ou óleo essencial de hortelã-pimenta (Mentha piperita L.) (Laszlo), Tween 80 (Vetec) e cloreto de cálcio (River), sob vigorosa agitação, por 10 minutos, à temperatura ambiente. 
Os revestimentos utilizados foram preparados em solução aquosa, constituindo os seguintes tratamentos:

Tratamento A: Controle (morango sem tratamento);

Tratamento B: glicerol $(1 \% \mathrm{v} / \mathrm{v})$, goma xantana $(0,5 \% \mathrm{p} / \mathrm{v})$;

Tratamento $\mathrm{C}$ : glicerol $(1 \% \mathrm{v} / \mathrm{v})$, goma xantana $(0,5 \% \mathrm{p} / \mathrm{v})$, ácido oleico $(0,5 \% \mathrm{v} / \mathrm{v})$, Tween $80(0,1 \% \mathrm{v} / \mathrm{v})$;

Tratamento D: glicerol $(1 \% \mathrm{v} / \mathrm{v})$, goma xantana $(0,5 \% \mathrm{p} / \mathrm{v})$, óleo essencial de hortelã-pimenta $(0,2 \% \mathrm{v} / \mathrm{v})$, Tween $80(0,1 \% \mathrm{v} / \mathrm{v})$;

Tratamento E: glicerol $(1 \% \mathrm{v} / \mathrm{v})$, goma xantana $(0,5 \% \mathrm{p} / \mathrm{v}), \mathrm{CaCl}_{2}(1 \% \mathrm{p} / \mathrm{v})$;

Tratamento F: glicerol $(1 \% \mathrm{v} / \mathrm{v})$, goma xantana $(0,5 \% \mathrm{p} / \mathrm{v})$, ácido oleico $(0,5 \% \mathrm{v} / \mathrm{v})$, Tween $80(0,1 \% \mathrm{v} / \mathrm{v}), \mathrm{CaCl}_{2}(1 \% \mathrm{p} / \mathrm{v})$;

Tratamento G: glicerol $(1 \% \mathrm{v} / \mathrm{v})$, goma xantana $(0,5 \% \mathrm{p} / \mathrm{v})$, óleo essencial de hortelã-pimenta $(0,2 \% \mathrm{v} / \mathrm{v})$, Tween $80(0,1 \% \mathrm{v} / \mathrm{v}), \mathrm{CaCl}_{2}(1 \% \mathrm{p} / \mathrm{v})$.

Os frutos foram totalmente submersos nas soluções por um minuto e, em seguida, drenados por dois a três minutos, utilizando-se de telas de náilon para que o excesso de solução fosse eliminado. Os frutos foram secos, sob ventilação forçada, a $4{ }^{\circ} \mathrm{C}$, por $15 \mathrm{~h}$, e após, foram embalados em bandejas com tampa de Polietileno Tereftalato (PET), padronizando o número de frutos por embalagem e armazenados a $4{ }^{\circ} \mathrm{C}$, durante 12 dias. Foram preparadas três bandejas para cada tratamento, em todos os tempos, contendo dez frutos por embalagem. As análises físicoquímicas e a incidência de fungos foram realizadas no dia do processamento das amostras (dia 0) e após 3; 5; 7; 10 e 12 dias de armazenamento, e as análises de antocianinas foram realizadas nos tempos $0 ; 5 \mathrm{e}$ 12 dias.

A incidência de fungos foi avaliada por inspeção visual, conforme Hernández-Muñoz et al. (2008). Os morangos que apresentaram qualquer sinal de desenvolvimento de micélio na superfície foram considerados deteriorados. Os resultados foram expressos como percentagem de morangos infectados.

A perda de massa foi obtida considerandose a diferença entre o peso inicial do morango revestido e aquele obtido ao final de cada tempo de armazenamento, de acordo com a fórmula: Perda de massa $=[($ massa inicial - massa final $) /($ massa inicial)] x 100. Foram realizadas quatro repetições, e a média dos resultados foi expressa em porcentagem de perda de massa.

A análise de firmeza foi realizada utilizando- se de penetrômetro manual com sonda de $5 \mathrm{~mm}$. As medições foram realizadas em dois pontos, em lados opostos, na zona equatorial de quatro frutos, por repetição. Os resultados foram expressos em Newtons (N).

A cor foi determinada utilizando-se de colorímetro Minolta CR 400. No padrão C.I.E $L^{*} a^{*} b^{*}$, a coordenada $\mathrm{L}^{*}$ expressa o grau de luminosidade da cor medida $\left(\mathrm{L}^{*}=100=\right.$ branco; $\mathrm{L}^{*}$ $=0=$ preto). Os valores $\mathrm{a}^{*} \mathrm{e} \mathrm{b}^{*}$ foram utilizados para calcular o ângulo Hue, ${ }^{\circ} \mathrm{h}^{*}=\arctan \left(\mathrm{b}^{*} / \mathrm{a}^{*}\right)$. Foram realizadas duas leituras em lados opostos, na região equatorial de quatro frutos, por repetição.

A partir dos frutos homogeneizados, foram realizadas as análises de $\mathrm{pH}$ (SCHOTT), acidez titulável, utilizando titulador automático (SCHOTT), e os sólidos solúveis em refratômetro digital (Atago PAL- 1) (AOAC, 1995). Foram realizadas três repetições. A acidez foi expressa como percentual de ácido cítrico $(\%)$, e os sólidos solúveis, em ${ }^{\circ}$ Brix.

Para a determinação do conteúdo de antocianinas totais, foi utilizada a metodologia proposta por Shin et al. (2007). A extração dos compostos antociânicos foi feita com metanol a $0,5 \% \mathrm{HCl}$ e, após, realizou-se a leitura em espectrofotômetro (Biospectro) em $515 \mathrm{~nm}$. Foram realizadas três repetições, e a média dos resultados, expressa em antocianinas totais (mg $\left.100 \mathrm{~g}^{-1}\right)$, em equivalentes de cianidina-3-glicosídio.

Com exceção da deterioração fúngica, os demais resultados foram submetidos à análise de variância, e a comparação de médias foi realizada pelo teste de Tukey, com nível de significância de 5\%, utilizando-se do programa SISVAR (FERREIRA, 1999). Para a descrição das variáveis em função dos períodos de armazenamento, foram realizadas análises de regressão polinomial.

\section{RESULTADOS E DISCUSSÃO}

Apenas os morangos submetidos aos tratamentos E, F e G, no tempo de 12 dias, apresentaram crescimento visível de fungos, cerca de $3 \%$ para os tratamentos $\mathrm{F}$ e $\mathrm{G}$ e de $6 \%$ para o tratamento E.

A ação do sanitizante e as condições higiênicas adotadas durante o processo minimizaram a deterioração fúngica nos tratamentos $\mathrm{A}, \mathrm{B}, \mathrm{C}$ e D. A ação antimicrobiana do ácido oleico, assim como do óleo essencial de hortelã-pimenta, não ficou evidente, visto que também não se observou deterioração fúngica da amostra-controle. Entretanto, a adição de cloreto de cálcio aos revestimentos $\mathrm{E}, \mathrm{F}$ e $\mathrm{G}$ estimulou o crescimento de fungos ao término 
do armazenamento.

Diversos trabalhos têm demonstrado alta porcentagem de deterioração fúngica em morangos, em poucos dias de armazenamento. $\mathrm{O}$ fungo acinzentado, Botrytis cinerea, é o patógeno pós-colheita de morango mais economicamente significativo (HERNÁNDEZ-MUÑOZ et al., 2008).

Diferentes comportamentos têm sido relatados sobre a influência do cálcio no crescimento de fungos em morangos revestidos. No estudo realizado por Han et al. (2004), a incidência de deterioração fúngica diminuiu significativamente nos morangos revestidos com quitosana adicionados de vitamina $\mathrm{E}$ ou lactato e gluconato de cálcio. O revestimento de quitosana adicionado de $0,2 \%$ de vitamina E mostrou os melhores resultados, pois, segundo os autores, a vitamina $E$ sela a superfície da fruta, enquanto os sais de cálcio, por serem umectantes, absorvem e retêm a umidade, tornando a superfície do morango mais úmida, o que favorece o crescimento fúngico. Influência semelhante do cálcio foi observada neste trabalho.

Entretanto, no estudo realizado por Hernández-Muñoz et al. (2008), comportamento diferenciado sobre a influência do cálcio foi relatada. De acordo com seus resultados, os morangos revestidos com $1,5 \%$ de quitosana isoladamente e com $0,75 \%$ de gluconato de cálcio não apresentaram crescimento fúngico aparente. De acordo com os autores, a incorporação de cálcio promove a ligação entre as homogalacturanas, fortalecendo a parede celular e a lamela média, que é a responsável pela união das células, o que pode melhorar a resistência a enzimas produzidas por fungos patogênicos.

Além disto, diferentemente da goma xantana, a quitosana apresenta a capacidade de inibir o crescimento de alguns fungos em determinadas concentrações. De acordo com Vargas et al. (2006), todos os revestimentos constituídos de 1\% de quitosana e diferentes concentrações de ácido oleico (1 a 4\%) diminuíram a infecção por fungos, em relação à amostra não revestida. Estes resultados sugerem que o ácido oleico aumenta a propriedade antimicrobiana da quitosana.

Em relação à influência de óleos essenciais, $\mathrm{Vu}$ et al. (2011) observaram incidência de fungos superior aos obtidos neste estudo, com a utilização de revestimentos de quitosana modificada e óleo essencial de limoneno ou hortelã-pimenta, obtendose em 14 dias de armazenamento, 100\% dos morangos deteriorados.

Houve aumento significativo da perda de massa dos morangos durante o armazenamento, independentemente do tratamento aplicado (Tabela
1). Entretanto, ao término do armazenamento, as amostras de morangos revestidas, ou seja, submetidas aos tratamentos B, C, D, E, F e G, apresentaram perda significativamente inferior à amostra-controle (A). Este tratamento apresentou a maior perda de massa, 20,99\%, após 12 dias de armazenamento. As amostras submetidas ao tratamento $\mathrm{G}$ apresentaram a menor perda, $6,88 \%$, enquanto as submetidas ao tratamento D apresentaram a maior perda entre as amostras revestidas, $14,09 \%$.

A adição de compostos lipídicos, ácido oleico ou óleo essencial de hortelã-pimenta, ao revestimento, não proporcionou uma redução significativa na perda de massa dos morangos, como era esperado. Em relação à adição do agente de firmeza cloreto de cálcio, apenas no tratamento $\mathrm{G}$, a perda de massa foi significativamente inferior ao respectivo tratamento $\mathrm{D}$, o qual não teve a adição deste componente.

Diversos autores que estudaram a influência, na perda de massa, de revestimentos à base de quitosana, aplicados a morangos, verificaram que o revestimento reduz a perda quando comparado com a amostra-controle. Entretanto, a influência da adição de compostos lipídicos e cálcio é controversa. Han et al. (2004) estudaram a influência da adição de vitamina $\mathrm{E}$ ou lactato e gluconato de cálcio ao revestimento de quitosana para reduzir a perda de peso de morangos armazenados a $2{ }^{\circ} \mathrm{C}$, por 14 dias, e verificaram que não houve diferença significativa entre os revestimentos, alcançando aproximadamente entre 10 e $11 \%$ de perda ao término do armazenamento. Ribeiro et al. (2007), ao avaliarem diferentes revestimentos em morangos (amido, carragena e quitosana com e sem adição de cálcio) armazenados entre 0 e $5^{\circ} \mathrm{C}$, durante 6 dias, observaram que a menor perda de peso, próximo a $3 \%$, foi obtida com quitosana e carragena, ambos com cloreto de cálcio. Já no estudo realizado por Hernández-Muñoz et al. (2008), com revestimento de morangos à base de quitosana e gluconato de cálcio, armazenados a $10{ }^{\circ} \mathrm{C}$, por 7 dias, foi observado que, no final do período de armazenamento, os morangos não tratados apresentaram perda de $28,7 \%$, enquanto as amostras revestidas com 1 e 1,5\% de quitosana perderam 19,6 e 14,2\%. Neste caso, a incorporação de cálcio não mostrou efeito significativo na redução da perda de peso dos morangos.

De acordo com a Tabela 1, não houve variação significativa nos valores de firmeza durante o armazenamento das amostras de morangos submetidos aos diferentes tratamentos. A influência do cloreto de cálcio não ficou evidente, visto que a firmeza da amostra-controle e aquelas sem a adição 
de cálcio foram semelhantes aos tratamentos em que o cálcio foi adicionado.

Costa (2009) também não observou a influência do cálcio na firmeza de morangos revestidos com quitosana, cloreto de cálcio, ácido oleico e/ou ácido esteárico durante todo o período de armazenamento. Comportamento diferente foi observado por Hernández-Muñoz et al. (2008), em que a adição de gluconato de cálcio ao revestimento de quitosana aumentou os valores de firmeza. De acordo com os autores, a presença de íons cálcio exógeno proporciona o aumento da pectina ionicamente ligada, contribuindo para a adesão célula-célula e a estabilidade da parede celular. Além disto, a quitosana utilizada isoladamente também exerceu um efeito benéfico sobre a firmeza dos morangos. Já no estudo realizado por Vargas et al. (2006), em que morangos foram revestidos com quitosana e diferentes concentrações de ácido oleico, os parâmetros de firmeza avaliados diminuíram durante o armazenamento, sendo atribuído à senescência do tecido, decomposição da parede celular, bem como perda de água da amostra. Não foram observados benefícios significativos da aplicação do ácido oleico neste parâmetro.

Não houve influência significativa do tempo nos valores de luminosidade dos morangos (Tabela 1). Entretanto, em relação à tonalidade para os tratamentos A, F e G, pode-se observar redução significativa em função do tempo de armazenamento (Tabela 1). Ao término do armazenamento, não houve diferença significativa nos valores de luminosidade e tonalidade dos morangos submetidos aos diferentes revestimentos. O brilho esperado pela utilização do revestimento não foi visualizado, assim como a opacidade pela adição dos compostos lipídicos. A tonalidade permaneceu na faixa do vermelho.

A manutenção da luminosidade de morangos parece ser dependente do revestimento aplicado, pois comportamento semelhante foi obtido por Ribeiro et al. (2007) e por Costa (2009) e, distinto, por Vargas et al. (2006) e Hernández-Muñoz et al. (2008). Em relação à tonalidade, Han et al. (2004), Vargas et al. (2006) e Hernández-Muñoz et al. (2008) não observaram mudança significativa nos valores.

Houve variação significativa dos valores de pH e acidez durante o armazenamento da amostracontrole (Tabela 2). Nos demais tratamentos, incluindo os resultados de sólidos solúveis dos morangos, não houve influência do tempo. Em relação à influência do revestimento, ao término do armazenamento, não houve diferença significativa nos valores de $\mathrm{pH}$, acidez e sólidos solúveis. Estes resultados mostram que os diferentes revestimentos foram efetivos na conservação dos morangos.

Comportamento semelhante foi observado por Vargas et al. (2006) e por Ribeiro et al. (2007). Já no estudo realizado por Han et al. (2004), pode-se observar aumento significativo do $\mathrm{pH}$ e redução da acidez com o tempo de estocagem, demonstrando a senescência dos frutos.

A aplicação dos diferentes revestimentos à base de goma xantana não alterou significativamente a concentração de antocianina dos morangos, quando comparados com a amostra-controle, como também não houve alteração com o tempo de armazenamento de 12 dias (Tabela 3).

Comportamento diferente foi observado por Vargas et al. (2006), em que a adição do ácido oleico, em diferentes concentrações no revestimento de quitosana aplicado a morangos, provocou redução no conteúdo de antocianinas durante o armazenamento refrigerado, enquanto não foram observadas alterações significativas na amostra-controle. No trabalho de Costa (2009), com revestimento de morango à base de quitosana, foi observado que, ao final do armazenamento de 15 dias sob refrigeração, os frutos que foram revestidos com quitosana e cloreto de cálcio obtiveram maior concentração de antocianina que a amostra sem revestimento. Os frutos cobertos com quitosana e ácido ascórbico apresentaram redução significativa no conteúdo de antocianinas durante o armazenamento; entretanto, nos morangos cobertos com cloreto de cálcio e ácido ascórbico, a redução não foi significativa. 


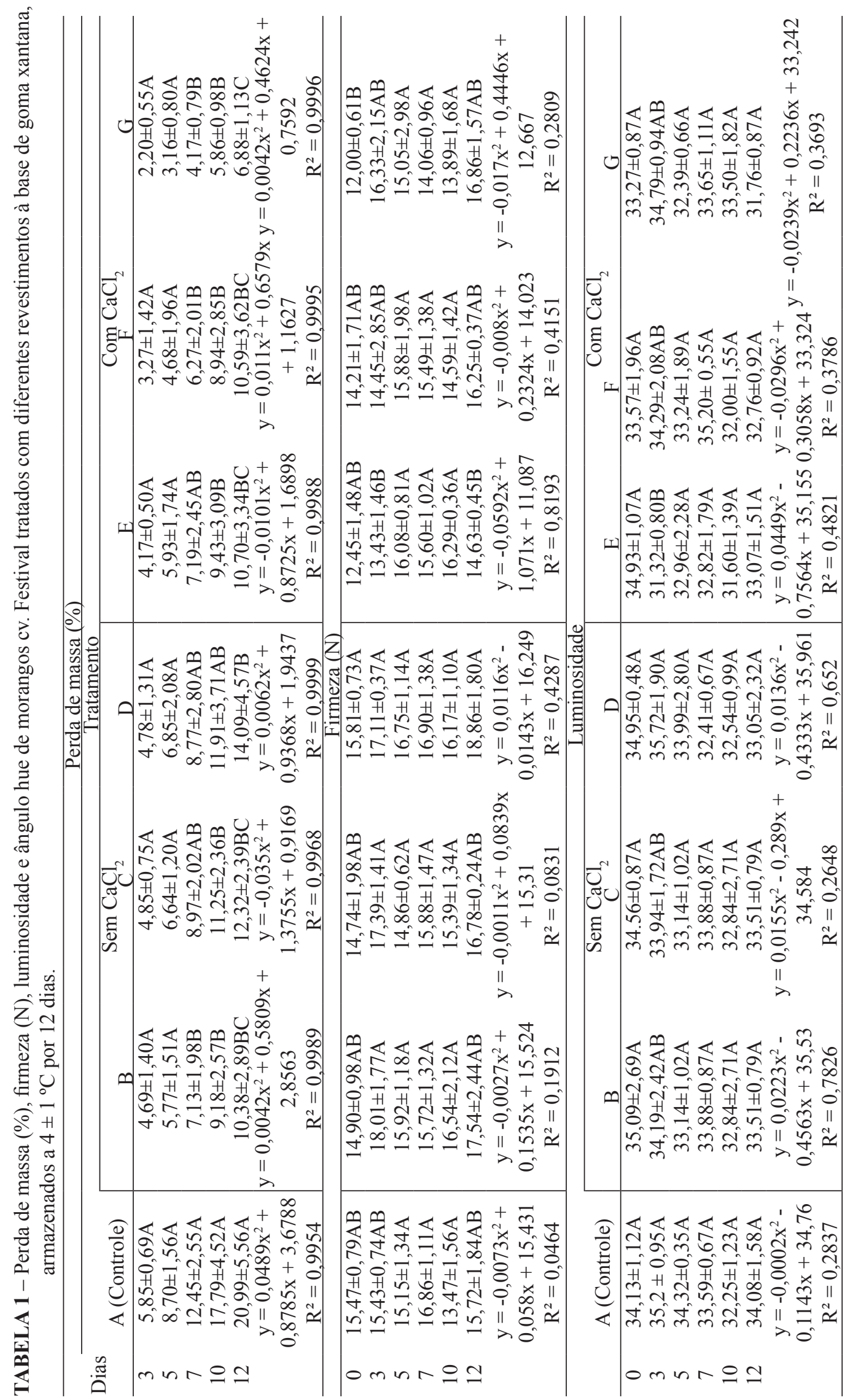

Rev. Bras. Frutic., Jaboticabal - SP, v. 37, n. 4, p. 1027-1036, Dezembro 2015 

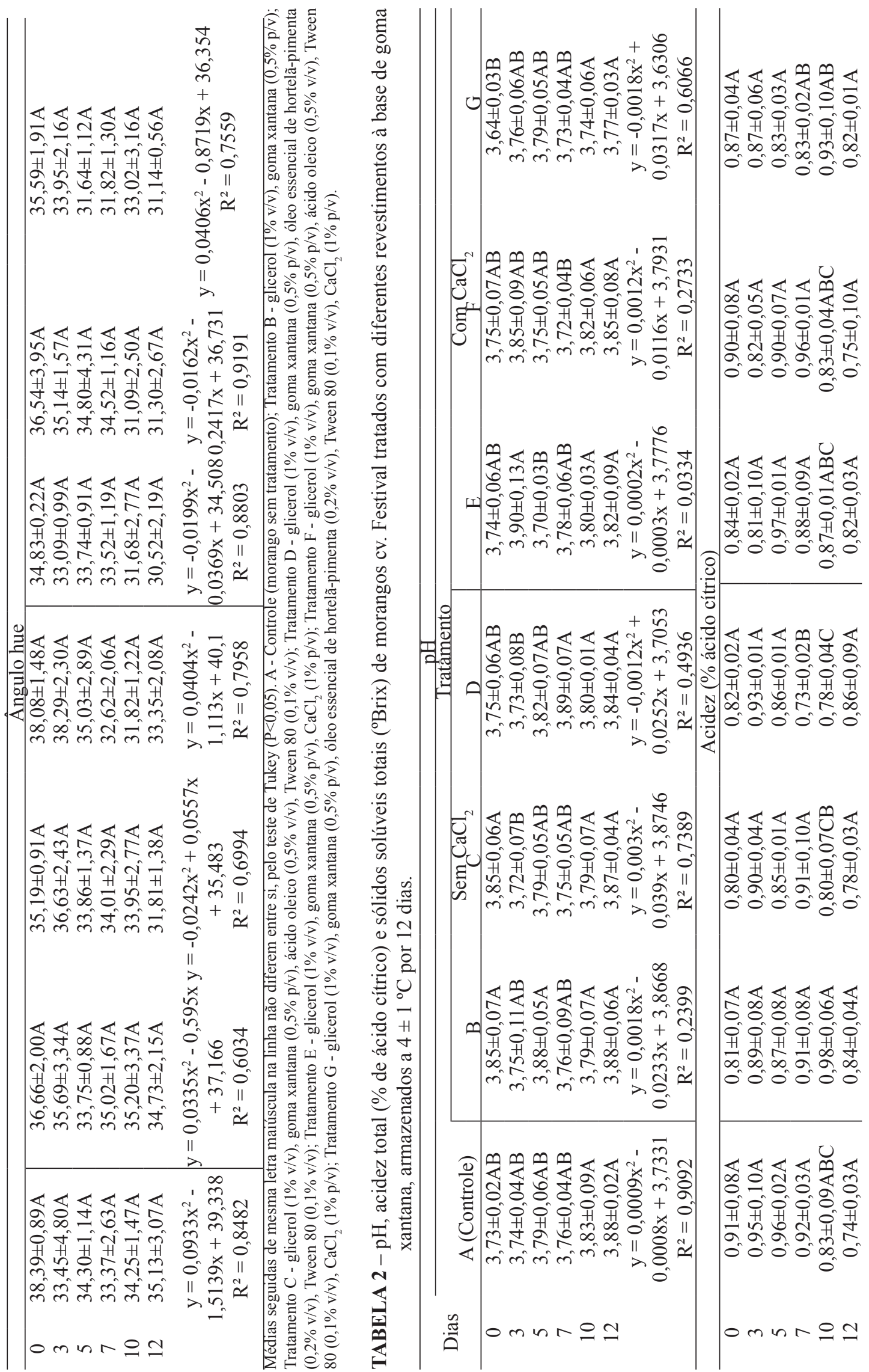


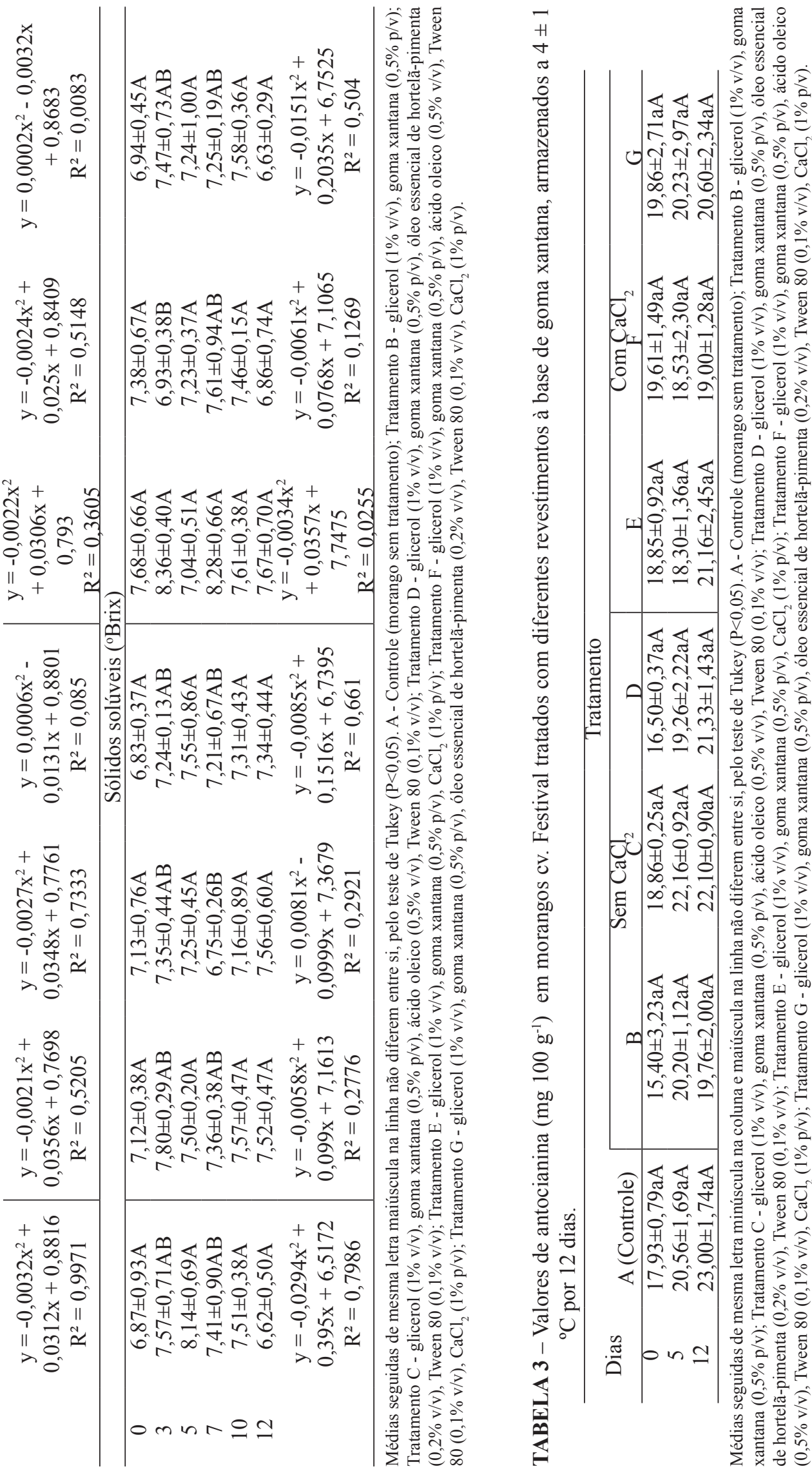




\section{CONCLUSÃO}

Os diferentes revestimentos utilizados neste trabalho são eficientes na conservação dos morangos. O tratamento com goma xantana e glicerol apresenta os melhores resultados, pois proporciona redução da perda de massa, manutenção da firmeza, cor, $\mathrm{pH}$, acidez, sólidos solúveis, antocianinas e não estimula o crescimento fúngico. A goma apresenta potencial para aplicação como revestimento em morangos cultivar Festival, armazenados sob refrigeração a 4 ${ }^{\circ} \mathrm{C}$, por 12 dias.

\section{REFERÊNCIAS}

AMARANTE, C.; BANKS, N.H. Postharvest physiology and quality of coated fruit and vegetables. In: JULES, J. Horticultural reviews. New York: John Wiley \& Sons, 2001. v. 26, p. 161-238.

AOAC - Association of Official Analytical Chemists. Official methods of analysis of the Association of Official Analytical Chemists. $16^{\text {th }}$ ed. Washington, 1995. 1094p.

BERBARI, S. A. G.; NOGUEIRA, J. N.; CAMPOS, S. D. S. Efeito de diferentes tratamentos précongelamento sobre a qualidade do morango var. Chandler congelado. Ciências e Tecnologia de Alimentos, Campinas, v.18, n. 1, p. 82-86, 1998.

BORGES, C. D.; MENDONÇA, C. R. B.; ZAMBIAZI, R. C.; NOGUEIRA, D.; SILVA, E. M. P.; PAIVA, F. F. Conservação de morangos com revestimentos à base de goma xantana e óleo essencial de sálvia. Bioscience Journal, Uberlândia, v. 29, n. 5, p. 1071-1083, 2013.

CAMPANIELLO, D.; BEVILACQUA, A.; SINIGAGLIA, M.; CORBO, M. R. Chitosan: Antimicrobial activity and potential applications for preserving minimally processed strawberries. Food Microbiology, Summit-Argo, v. 25, n. 8, p. 992-1000, 2008.

CORTEZ-VEJA, W. R.; PIOTROWICZ, I. B. B.; PRENTICE, C.; BORGES C. D. Conservação de mamão minimamente processado com uso de revestimento comestível à base de goma xantana. Semina: Ciências Agrárias, Londrina, v. 34, n. 4, p.1753-1764, 2013.
COSTA, C. S. Coberturas à base de quitosana na qualidade pós-colheita de morango cv. Aromas. 2009. 107 f. Tese (Doutor) - Universidade Federal de Pelotas, Pelotas, 2009.

DAVIDSON, W.S.; SAXENA, R.K.; GUPTA, R. The fungistatic action of oleic acid. Current Science, Balgalori, v. 76, n.8, p.1137-1139, 1999.

DEL-VALLE, V.; HERNÁNDEZ-MUÑOZ, P.; GUARDA, A.; GALOTTO, M. J. Development of a cactus-mucilage edible coating (Opuntia ficus indica) and its application to extend strawberry (Fragaria ananassa) shelf-life. Food Chemistry, Whiteknights, v. 91, n. 4, p.751-756, 2005.

FAN, Y.; XU, Y.; WANG, D.; ZHANG, L.; SUN, J.; ZHANG, B. Effect of alginate coating combined with yeast antagonist on strawberry (Fragaria $\times$ ananassa) preservation quality. Postharvest Biology and Technology, Amsterdam, v. 53, n. 1-2, p. 84-90, 2009.

FERREIRA, D. F. Sistema de análise de variância (SISVAR). Versão 4.6. Lavras: Universidade Federal de Lavras, 1999.

FREITAS, I. R.; CORTEZ-VEJA, W. R.; PIZATO, S.; PRENTICE-HERNÁNDEZ, C.; BORGES, C. D. Xanthan gum as a carrier of preservative agents and calcium chloride applied on fresh-cut apple. Journal Food Safety, New Brunswick v.33, n.3, p. 229-238, 2013.

GARCÍA-OCHOA, F.; SANTOS, V.E.; CASAS, J. A.; GÓMEZ, E. Xanthan gum: production, recovery and properties. Biotechnology Advances, Ontario, v. 18 , n. 7, p. 549-579, 2000.

HAN, C.; ZHAO, Y.; LEONARD, S. W.; TRABER, M. G. Edible coatings to improve storability and enhance nutritional value of fresh and frozen strawberries (Fragaria $\times$ ananassa) and raspberries (Rubus ideaus). Postharvest Biology and Technology, Amsterdam, v. 33, n.1, p. 67-78, 2004.

HENRIQUE, C. M.; CEREDA, M. P. Utilização de biofilmes na conservação pós-colheita de morango (Fragaria Ananassa Duch) cv IAC Campinas. Ciência e Tecnologia de Alimentos, Campinas, v.19, n. 2, p. 231-233, 1999. 
HERNÁNDEZ-MUÑOZ, P.; ALMENAR, E.; DEL VALLE, V.; VELEZ, D.; GAVARA, R. Effect of chitosan coating combined with postharvest calcium treatment on strawberry (Fragaria $x$ ananassa) quality during refrigerated storage. Food Chemistry, Whiteknights, v. 110, n. 2, p. 428-435, 2008.

HERNÁNDEZ-MUÑOZ, P.; ALMENAR, E.; ÓCIO, M. J.; GAVARA, R. Effect of calcium dips and chitosan coatings on postharvest life of strawberries (Fragaria $\mathrm{x}$ ananassa). Postharvest Biology and Technology, Amsterdam, v. 39, n. 3, p. 247-253, 2006.

KROCHTA, J. M.; MULDER-JOHNSTON, C. Edible and biodegradable polymer films: challenges and opportunities. Food Technology, Chicago, v. 51, n.2, p. 61-74, 1997.

OLIVEIRA, C. M.; SILVA, O. F.; SILVA, M. C.; RÉGIS, S. A.; CABRAL, L. M. C.; CENCI, S. A. Utilização do soro de leite bovino como revestimento protetor em morangos. Boletim CEPPA, Curitiba, v. 26, n. 2, p. 187-196, 2008.

PEREIRA, M. C.; VILELA, G. R.; COSTA, L. M. A. S.; SILVA, R. F.; FERNANDES, A. F.; FONSECA, E. W. N.; PICCOLI, R. H. Inibição do desenvolvimento fúngico através da utilização de óleos essências de condimentos. Ciência e Agrotecnologia, Lavras, v. 30, n. 4, p. 731-738, 2006.

PIZATO, S.; CORTEZ-VEGA,W. R.; DE SOUZA, J. T. A.; PRENTICE-HERNÁNDEZ, C.; BORGES, C. D. Effects of different edible coatings in physical, chemical and microbiological characteristics of minimally processed peaches (Prunus persica $(L$.) Batsch). Journal of Food Safety, New Brunswick, v.33, n.1, p.30-39, 2013.

RIBEIRO, C.; VICENTE, A. A.; TEIXEIRA, J. A.; MIRANDA, C. Optimization of edible coating composition to retard strawberry fruit senescence. Postharvest Biology and Technology, Amsterdam, v. 44, n.1, p. 63-70, 2007.
SHIN, Y.; LIU, R. H.; NOCK, J. F.; HOLIDAY, D.; WATKINS, C. B. Temperature and relative humidity effects on quality, total ascorbic acid, phenolics and flavonoid concentrations, and antioxidant activity of strawberry. Postharvest Biology and Technology, Amsterdam, v. 45, n. 3, p. 349-357, 2007.

SINGH, R.; SHUSHNI, M. A.M.; BELKHEIR, A. Antibacterial and antioxidant activities of Mentha piperita L. Arabian Journal of Chemistry, Riyadh, v.4, n.1, p.1-20, 2011.

TANADA-PALMU; P. S.; GROSSO, C. R. F. Effect of edible wheat gluten-based films and coatings on refrigerated strawberry (Fragaria ananassa) quality. Postharvest Biology and Technology, Amsterdam, v. 36, n. 2, p. 199-208, 2005.

VARGAS, M.; ALBORS, A.; CHIRALT, A.; GONZÁLEZ-MARTÍNEZ, C. Quality of cold-stored strawberries as affected by chitosan-oleic acid edible coatings. Postharvest Biology and Technology, Amsterdam, v. 41, n. 2, p. 164-171, 2006.

VU, K. D.; HOLLINGSWORTH, R. G.; SALMIERI, S.; LACROIX, M. Development of edible bioactive coating based on modified chitosan for increasing the shelf life of strawberries. Food Research International, Toronto, v. 44, n.1, p. 198-203, 2011.

YADEGARINIA, D.; GACHKAR, L.; REZAEI, M. B.; TAGHIZADEH, MASSOUD; ASTANEH, S. A.; RASOOLI, I. Biochemical activities of Iranian Mentha piperita L. and Myrtus communis L. essential oils. Phytochemistry, Washington, v. 67, n. 12, p. 1249-1255, 2006. 